\title{
MIR1208 Pre-miRNA
}

National Cancer Institute

\section{Source}

National Cancer Institute. MIR1208 Pre-miRNA. NCI Thesaurus. Code C118129.

MIR1208 Pre-miRNA (73 bases) is encoded by the human MIR1208 gene. This

oligoribonucleotide may play a role in transcriptional silencing. 